\title{
Web-Monitoring Module for the Xilema Suria Video Surveillance System
}

\author{
Denis Luis Espinosa Pérez, Eng. ${ }^{1}$, Eliecer Sánchez Ramírez, Eng. ${ }^{1}$, Julio Jesús Garcia Coste, Eng. ${ }^{1}$, and Yunior \\ Camilo Cabrera Domínguez, Eng. ${ }^{1}$ \\ ${ }^{1}$ Informatics Sciences University, Cuba, dlespinosa@uci.cu, eliecersr@uci.cu, jjcoste@uci.cu
}

\begin{abstract}
Xilema Suria is a video surveillance system, which allows the monitoring, analysis and control of video surveillance IP cameras. It was designed as a modular system that allows the integration of different components and it is developed to be used in desktop environments. This kind of design restricts its used to the monitoring seasons where the visor module be installed. Moreover it decreases its availability and accessibility from other network points. The current paper describes a solution alternative to the problems mentioned before starting from the implementation of a web application for the monitoring, analysis of the video flows emitted by the IP cameras as well as the control of these ones by means of the used of a plugin architecture-based. To develop the application the JavaScript Ext JS framework 4.2.7, the PHP 5.4 programming language as well as the VLC web plugin for its visualization was used. A camera control plugin to the Vivotek PT 7135 was developed by creating the bases for the development of new plugins for the control of other camera modules.
\end{abstract}

Keywords - video surveillance, cameras, monitoring, web

Digital Object Identifier (DOI): http://dx.doi.org/10.18687/LACCEI2015.1.1.139

ISBN: 13 978-0-9822896-8-6

ISSN: $2414-6668$

$1^{\text {th }}$ LACCEI Annual International Conference: “Engineering Education Facing the Grand Challenges, What Are We Doing?” July 29-31, 2015, Santo Domingo, Dominican Republic ISBN: 13 978-0-9822896-8-6

ISSN: 2414-6668

DOI: http://dx.doi.org/10.18687/LACCEI2015.1.1.139 


\section{Web-monitoring module for the Xilema Suria video surveillance system}

Denis Luis Espinosa Pérez, Informatics Sciences Engineer ${ }^{1}$, Eliecer Sánchez Ramírez, Informatics Sciences Engineer, Julio Jesús Garcia Coste, Informatics Sciences Engineer ${ }^{1}$ and Yunior Camilo Cabrera Domínguez, Informatics

Sciences Engineer ${ }^{4}$

${ }^{1}$ Informatics Sciences University, Cuba, dlespinosa@uci.cu, jjcoste@uci.cu

${ }^{2}$ Informatics Sciences University, Cuba, eliecersr@uci.cu

\begin{abstract}
Xilema Suria is a video surveillance system, which allows the monitoring, analysis and control of video surveillance IP cameras. It was designed as a modular system that allows the integration of different components and it is developed to be used in desktop environments. This kind of design restricts its used to the monitoring seasons where the visor module be installed. Moreover it decreases its availability and accessibility from other network points. The current paper describes a solution alternative to the problems mentioned before starting from the implementation of a web application for the monitoring, analysis of the video flows emitted by the IP cameras as well as the control of these ones by means of the used of a plugin architecture-based. To develop the application the JavaScript Ext JS framework 4.2.7, the PHP 5.4 programming language as well as the $V L C$ web plugin for its visualization was used. A camera control plugin to the Vivotek PT 7135 was developed by creating the bases for the development of new plugins for the control of other camera modules.
\end{abstract}

Keywords-- video surveillance, cameras, monitoring, web

\section{INTRODUCTION}

Nowadays, the video surveillance is a rational solution to security problems faced by the society. The possibility of having lots of cameras connected to each other with functions from the facial recognition and monitoring, video recordings or making real-time visualizing until duties monitoring, acts of violence, people and plates identification, malls and schools surveillance are important advantages that could be obtained as a result of video surveillance systems.

Those systems have as a main purpose, to visualize the video flows from IP cameras in real time (1), getting that the security personal in charge of taking appropriate decisions in case of any problem. This process is known as monitoring in the video surveillance field. Systems are generally installed in a monitoring station which is a hardware location located in a fixed localization in the installation posted to this action previously.

Investigation in the video surveillance software development has started in Cuba. At Geoinformatic and Digital signals Center, which belongs to school 6 from the Informatics Sciences University, the Xilema Suria product is developed. This video surveillance system offers functionalities for the video and flows management processing emitted by a set of installed cameras. The system is composed of the following modules:

- Recorder, in charge of recording the video flows emitted by the cameras connected to the system.

- Returner, in charge of visualizing the video flows saved by the recorder.

- Analysis, to run different video sensors over the video flows.

- Autonomy, with the function of orchestrate the processes occurred in the system as well as the communication among the different modules.

- Visor, in charge of visualizing the flows from the IP cameras, to serve as an interface for the functionalities that offer the other modules.

The system has a plugins ${ }^{1}$-based architecture, which allows the use of a wide IP video surveillance camera models. To visualize the video flows emitted by the video surveillance IP $1^{\text {th }}$ LACCEI Annual International Conference: “Engineering Education Facing the Grand Challenges, What Are We Doing?” July 29-31, 2015, Santo Domingo, Dominican Republic DOI: http://dx.doi.org/10.18687/LACCEI2015.1.1.139 
cameras using the Xilema Suria system, is necessary to install the Visor module in a monitoring station. Its installing process can be an annoying task for users with a little knowledge about the theme because of is necessary to know a set of setting parameters and make a set of steps in order to the product works efficiently.

Besides, the designed monitoring station should have enough storing space for the installation of the Visor module and all its dependencies, making the use of light customers and mobile devices impossible. As a result, in case of being necessary the use of the module from another network terminal, the installing process will make again itself as long as it has the necessary hardware requirements. All this bring as a result that the Xilema Suria system has availability problems, which seriously affects the accessibility levels from any network terminal to its functionalities. From this appropriate evidence on, to develop a monitoring web module for the video surveillance Xilema Suria was decided.

Among the video surveillance systems some applications can be mentioned such as: Cisco Video Surveillance Operations Manager from Cisco, being one of the most important in the video surveillance market. This application provides a web interface to set, manage, visualize and control the video flow coming from the IP cameras in a local network. By using a privative license it is distributed to the users and the fact of adding cameras to the system, which are developed by the own Cisco company is one of the mean disadvantages of this application.

In the other hand, Vidium is a SaaS (Software as Service) solution. It is about an online platform of IP cameras video surveillance. It is multiplatform and it does not require additional software to be used. The system is able to generate alerts by means of SMS (Short Message Service) or e-mail taking into consideration the different events could be able to occur such us: movement detection or power outages. This application is developed by the Spanish Company Vidium Surveillance Online S.L. It requires that all the emplacement to be connected to Internet directly what make impossible the use of the system in a private network. This characteristic is one of the most significant disadvantages of this application.

The study about these systems and about its features helped as a starting point in the development of this research, as well as the analysis of the mean disadvantages they have allowed to work out a solution, which does not have the limiting mentioned before, enlarging this way its added value

\section{MATERIALS AND METHODS}

The monitoring module has the following functionalities: to manage the manager setting, to authenticate the user, to handle the camera, to establish static visualization mode, to establish personalized visualization mode, to manage functions of a video flow, to show visualizer independently, to check connection with the manager and close session.

The customer stations should use Moxilla Firefox version 28.0 as a web browser, Google Chrome 32.0, Opera 20.0, Safari 5.1 or any higher version to access to the system. The VLC Web Plugin in its version 2.0 must be installed. The applications server where the web-monitoring module will be placed should has Apache in its version 2.22 or higher and PHP 5.3.8.

In order to have a better system comprehension is necessary that the conceptual framework to be presented, the monitoring by using the web visor module in the Xilema Suria System. The classes, which compose the diagram from the frame 1, are described below.

- User: person in charge of working with the Visor module.

- Visor: Module from the Xilema Suria system, which allows the visualization of the video flows emitted by IP cameras. It interacts with thee Manager Module, too.

- Video flows: continuous video sequence, which is emitted by an IP camera.

- Camera: device for the video flows emission. 
- Manager: Module from the Xilema Suria system in charge of orchestrating the processes.

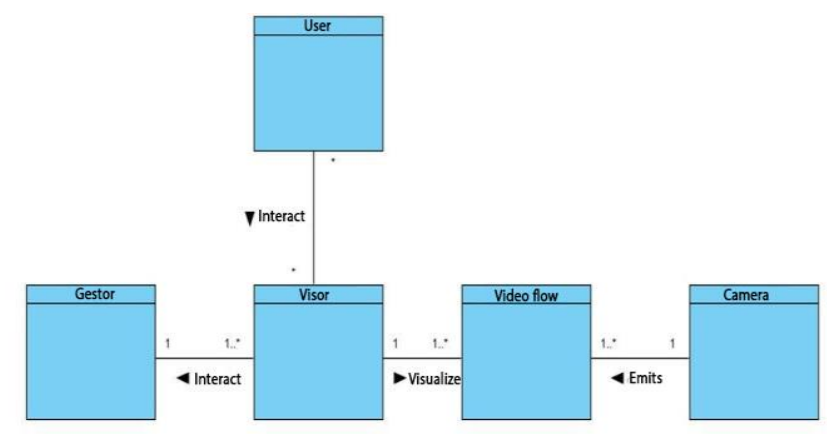

Fig 1. Domain model.

A user starts the monitoring process, which use the webmonitoring module (Visor). It is installed in a monitoring station, which should be connected in a local area in order to the video flows process could be carried out. From this module the video flows emitted by several cameras can be visualize and handle. It interacts with a Manager Module, which is in charge of orchestrating the processes of the Xilema Suria system.

For the construction of the system was used the RUP methodology taking into consideration that it generates a series of artifacts that will facilitate the work of implementation (Ibargollín, 2012) (9). Another important factor to consider for the election is the need for integration of the proposed solution documentation with the Xilema Suria system, in which this methodology is used. The making of the application is based on the use of free tools. According to the above approach is decided to use as client side languages: HTML 5, JavaScript and ExtJS 4.2.7, whereas the server-sides are PHP 5.3.8 and PHP NuSOAP library for communication with the rest of the system modules. VLC Web Plugin 2.0 is used for displaying video streams.

Then the above technologies are described.

- HTML 5: HTML, Hyper Text Markup Language, is the language in which web pages are written. It lets you type text in a structured way and consists of tags that mark the beginning and the end of each element of the document (11).

- JavaScript: It is an interpreted programming language. It is mainly used because the framework is developed with JavaScript (12).

- ExtJS 4.2.7: is a framework that allows developing applications with a high level of complexity, based on the use of predefined components in the framework. They have a high degree of configuration and adaptability to the required needs and that are possible to adapt thanks to handle designs having (2). It also allows the development of applications using the Model View Controller architecture, MVC.

- PHP 5.3.8: it is a programming language interpreted by a web server that executes the statements without compiling. It is widely used worldwide in the development of dynamic web applications. Their sentences are incorporated within the HTML code (10).

- NuSOAP: is a PHP library that allows the creation and consumption of web services based on SOAP 1.1, WSDL 1.1 and HTTP 1.0 / 1.1 (13).

- VLC Web Plugin 2.0: dissimilar allows playback of multimedia formats, offers advantages for working with audio and video streams through the network, with support for a wide range of protocols (14). The demand for resources during operation is low. It allows playback of video streams using the RTSP protocol, which is the standard for IP video surveillance cameras.

The style of software architecture used was the MVC because of it separates the application source code into three groups: Model, View and Controller. The model will be responsible for communicating with the data and business logic, and the controller will be responsible for receiving input events from the view (6). 


\section{ADVANTAGES OF THE SURVEILLANCE VIDEO SYSTEMS DEVELOPED WITH WEB TECHNOLOGIES.}

With the growing inclination towards web technologies, according to the advantages and the importance that has taken the Net for people, the video surveillance applications have begun to migrate to this environment (5). The benefits of web technologies in video surveillance systems make them more competitive in the market for this type of software worldwide. The video surveillance systems on the web incorporate the following benefits:

- The user can easily access to these applications using a web browser.

- It allows the access anytime, from anywhere in the world where you have a network connection where the system to be installed.

- You can update and maintain a single application and all users will see the results immediately. Users do not have to update it.

- Technologies that enable portability between different platforms are used. Compatibility problems are reduced.

- A little or no disk space is required. They can be accessed from network terminals diskless or with a very low storage space.

\section{VISUALIZATION ON THE WEB OF THE VIDEO}

\section{FLOWS EMITTED BY IP CAMERAS.}

IP cameras can emit video and audio flows. They are accessible through URL $^{1}$ addresses created by the software that controls the camera. It is generally required the authentication to access them and they are emitted in formats, which do not generate a relevant traffic on the Net. There are several technologies on the Web for the visualization of video flows coming from IP cameras or from others sources such as multimedia servers. Besides, it provides several solutions for the visualization and managing of the audiovisual contents.
One of these tools is the VLC Web Plugin, which is a complement installed in the browsers for the multimedia contents reproduction. It is capable to reproduce video flows, which use the protocols generally used by the IP cameras for transmission, such as RSTP and HTTP and the handling of the audio and video characteristics. In the other hand, HTML 5 has a video element for the multimedia reproduction on the Web. It is highly settable and adaptable to different contexts. Moreover, it allows the video flows reproduction by using the HTTP protocol but nowadays, it is not capable to reproduce flows that use the RSTP protocol.

\section{HANDLING OF IP CAMERAS SETTING PARAMETERS FROM THE WEB}

IP cameras provide a series of settings, which allow the personalization for different contexts, according to the willing and functions they have. Such settings are accessed and modified by the software that controls them or outside systems through different parameters.

The parameters are in charge of providing information about the camera such as: model, name, IP address, or modifying their specifications such as: images fit, audio, video characteristics and others specifications. The access to such parameters is generally made by mean of a URL defined by the manufacturer. Because of this, the way to access and modify the parameters of an IP camera changes, so that each camera model should be treated in a unique way.

\section{RESULTS AND DISCUSSION}

In the deployment diagram the physic disposition of the different elements are shown. They are known as nodes, which take part in the process and the existing relationships among them (3). Making the graphic of the physic environment where the video process is developed, different key issues can be understood like the system distribution, which influence directly in the implementation. The nodes that compose the deployment diagram are described below. Monitoring station: net terminal from which a user makes use of the webmonitoring module by mean of a browser. Web server: server where the web-monitoring module will be placed. Camera: 
device in charge of emitting video flows. Applications server: server where the Xilema Suria system Manager module will be placed.

The access to the web-monitoring module happens from a monitoring station. It is placed in a web server and establish the connection with the Manager module, which is available in an applications server. Both connection security are ensured by using the HTTPS protocol. In the web-monitoring module, the video flows emitted by the integrated cameras can be visualized and the ones that have an associated plugins can be controlled. For this process, the RTSP and HTTP protocols are used. The deployment diagram proposed for the webmonitoring module is presented below.

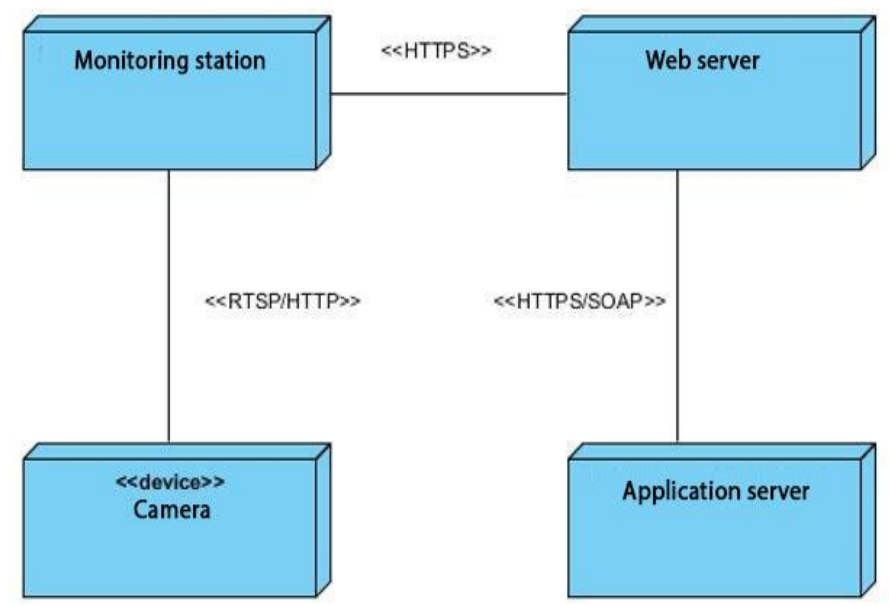

Fig 2: Deployment Diagram

To use the Visor module is necessary first to set the connection parameters with the Manager module. Once having tested and stored properly the Manager module setting, the user can authenticate and access to the system. In the frame 3, the start interface of the web Visor module is shown.

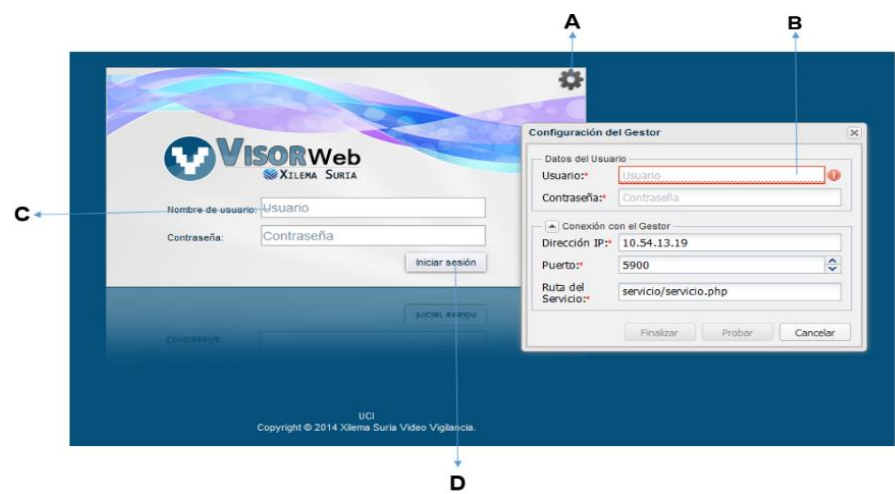

Fig 3. Start interface of the Xilema Suria system web Visor module.

Description per areas of the start interface of the Xilema Suria system web Visor module.

A) Manager setting: it allows accessing to the setting form of the connection parameters with the Xilema Suria system Manager module.

B) Manager setting: it allows setting the connection with the Manager module, testing and storing the setting parameters.

C) Authentication form: it allows the user to introduce the authentication data.

D) Session starting: A button that allows the user start the session in the web Visor module.

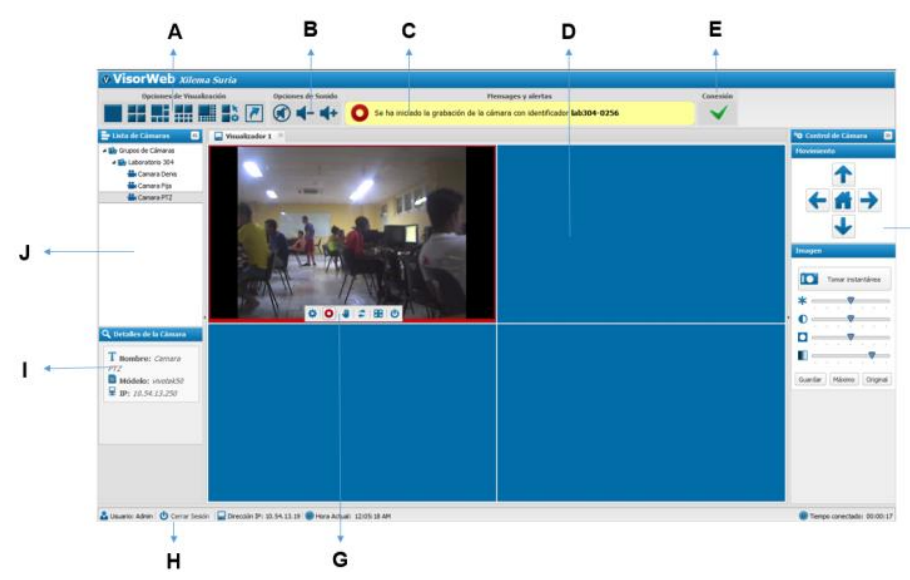

Fig 4. User graphic interface of the Xilema Suria system web Visor module.

Description per areas of the start interface of the Xilema Suria system web Visor module.

13 ${ }^{\text {th }}$ LACCEI Annual International Conference: "Engineering Education Facing the Grand Challenges, What Are We Doing?" 
A) Visualization options: it allows the user to choose a static visualization mode. In the area, the options that allow using the personalized modes designer and the one to show the visualization mode independently are also found.

B) Sound options: area that allows the volume control of the cameras that are visualizing themselves in that moment.

C) Messages and alerts: in this area the system notifications are shown to the user.

D) Visualization panel: an area where the different visualization modes chosen by the user are loaded.

E) Connection: the connection state with the Xilema Suria system Manager module is shown.

F) Camera control: in this area, the corresponding plugin to the camera model wanted to control is shown to the user. The visual interfaces are built by each camera plugin specifically and they change according to functionalities the camera has.

G) Operations menu: it allows managing the functions of any video flow. From it, starting the recording tasks, movement recognition, controlling IP cameras, recharging video flows, maximizing the camera views and closing the visualizations could be ordered.

H) Information panel: it provides useful information to the user as for example: the current time, the time stayed authenticated in the system and the IP address from which they have been accessing to the web Visor module. In this area, the "Close session" option is located.

I) Details: the corresponding information to the chosen camera is shown: name, model, IP address, and others. It also shows extra information corresponding to the camera groups and to the system.
J) Cameras list: It shows the cameras list available in the system. They can be visualized when dragging them and letting them go of one of the visualizing divisions.

\section{CONCLUSIONS}

With the introducing of the web-monitoring module, the Xilema Suria system decreased its scalability and availability problems. The aggregate value of the system increased when adding it new possibilities of IP video surveillance cameras control and possibilities from others net terminals. The use of computational resources from client side allowed a better hardware use of the monitoring stations. The proposed solution is new regarding the use of web technologies, working as a complement to the traditional video surveillance software. A base-plugin architecture allows the system to handle lots of IP video surveillance camera models, what make achievable its use in areas where different types of camera is had. The use of ExtJS framework offers an easy interface to handle by the system operators and its significant latency times for emplacement are less than 12 cameras

\section{REFERENCES}

1. Marrero, Danieyis Santiago y Pereira, Pedro Orlando Acosta. Repositorio Institucional. Repositorio Institucional. [En línea] noviembre de 2011. [Citado el: 1 de diciembre de 2013.] http://repositorio_institucional.uci.cu/jspui/handle/ident/TD_04525_11.

2. SENCHA INC. Sencha Ext JS. JavaScript Framework for Rich Desktop Apps. [En línea] [Citado el: 6 de http://www.sencha.com/products/extjs/.

3. IBM. Rational Method Composer. Classic RUP for SOMA. [pdf] 2007.

4. Larman, Craig. [En línea] 2003. [Citado el: 5 de marzo de 2014.] http://is.ls.fi.upm.es/docencia/is2/documentacion/ModeloDominio.pdf.

5. Mora, Sergio Luján. Programación de aplicaciones web: historia, principios básicos y clientes web. s.l. : Editorial Club Universitario. ISBN978-84-8454-206-3.

6. Potencier, Fabien. LIBROSWEB. LIBROSWEB. [En línea] 2013. [Citado el: 10 de diciembre de 2013.] http://librosweb.es/symfony_2_3/.

13 $^{\text {th }}$ LACCEI Annual International Conference: "Engineering Education Facing the Grand Challenges, What Are We Doing?" July 29-31, 2015, Santo Domingo, Dominican Republic 
7. ICANSEE. ICANSEE - Camaras Videovigilancia. ICANSEE - Camaras Videovigilancia. [En línea] 12 de septiembre de 2012. [Citado el: 2 de diciembre de 2013.] http://www.icansee.es/blog/.

8. Communications, Axis. Axis Communications. Axis Communications. [En línea] 2013. [Citado el: 3 de diciembre de 2013.] http://www.axis.com/academy/web-based.htm.

9. Ibargollín, Neybel González. Repositorio Institucional de la UCI. Módulo de análisis para el sistema de vídeo vigilancia Suria en Qt. La Habana: Universidad de las Ciencias Informáticas, 2012.

10. PHP. PHP. PHP. [En línea] 2013. [Citado el: 5 de diciembre de 2013.] http://www.php.net/.

11. Desarrolloweb. Desarrolloweb. Desarrolloweb. [En línea] 14 de mayo de 2012. [Citado el: 6 de dicembre de 2013.] www.desarrolloweb.com.

12. Valdés, Damian Pérez. Maestros del Web. Maestros del Web. [En línea] 2007. [Citado el: 6 de diciembre de 2013.] http://www.maestrosdelweb.com/editorial/\%C2\%BFque-es-javascript/.

13. W3C Recommendation. W3C. W3C. [En línea] 27 de abril de 2007. [Citado el: 4 de 12 de 2013.] http://www.w3.org/TR/2007/REC-soap12part0-20070427/.

14. VideoLAN, Wiki. VideoLAN's Wiki. VideoLAN's Wiki. [En línea] 2013.

[Citado el: 4 de diciembre de 2013.] https://wiki.videolan.org/.

15. Ashworth, Stuart y Duncan, Andrew. Ext JS 4 Web Application Development Cookbook. Birmighan-Mumbai : Packt Publishing Ltd, 2012. ISBN 978-1-84951-686-0.

16. Ruíz. Página personal de Rafael Ruíz. [En línea] 29 de noviembre de 2010. [Citado el: 4 de abril de 2014.] http://rafaeska.es/algo-que-anadir//blogs/usando-jmeter-para-el-estres-web.

17. Vidium Wiki. Vidium Wiki y documentación. Vidium Wiki y documentación. [En línea] 2013. [Citado el: 4 de diciembre de 2013.] https://sites.google.com/a/vidium.es/vidium-wiki/.

18. Berners-Lee, T., y otros. Internet Engineering Task Force(IETF). Request for Comments-Hypertext Transfer Protocol. [En línea] 2000. [Citado el: 5 de diciembre de 2013.] http://tools.ietf.org/html/rfc2616.

19. Eguiluz, Javier. LIBROSWEB. LIBROSWEB. [En línea] 2007. [Citado el: 6 de diciembre de 2013.] http://librosweb.es/ajax/index.html.

20. Hakansson, Maria. Human-Computer Interaction. s.1. : IT-university, 2005.

13 ${ }^{\text {th }}$ LACCEI Annual International Conference: "Engineering Education Facing the Grand Challenges, What Are We Doing?" July 29-31, 2015, Santo Domingo, Dominican Republic 